J. Lake Sci. (湖泊科学) , 2011, 23(6): 991-996

http: //www.jlakes.org. E-mail : jlakes@niglas.ac.cn

(C) 2011 by Journal of Lake Sciences

\title{
东江流域典型子流域土地利用/覆被变化对地表径流影响"
}

\author{
杨宏伟 ${ }^{1,2}$, 许崇育 ${ }^{1}$ \\ (1: 南京大学地理与海洋科学学院, 南京 210093) \\ ( 2 : 中国科学院南京地理与湖泊研究所, 南京 210008)
}

摘 要: 应用 SWAT 模型对东江上中下游典型流域的地表径流进行模拟,采用 1977-1981 年和 1996-2000 年胜前、顺天 和九州三个出口控制站逐月实测径流资料进行模型校准和验证, 确定模型的敏感性参数, 采用相关系数 $R^{2}$ 和 Nash-Suttclife 模型效率系数 $E_{\mathrm{NS}}$, 对 SWAT 模型模拟结果进行评价, 结果显示模拟精度较高, $R^{2}>0.85, E_{\mathrm{NS}}$ 在 $0.68-0.75$ 之间. 在 此基础上进一步探讨了典型流域土地利用变化对地表径流的影响,研究认为林地面积的增加可导致年径流量减少; 年内 分配上枯水期径流明显增加,丰水期径流明显减少; 小于 $15^{\circ}$ 的林地面积增加引起的径流减少作用更为明显.

关键词: SWAT 模型;土地利用/覆被变化;地表径流; 东江典型流域

\section{Effect of LUCC on runoff of three representative watersheds in Dongjiang River Basin}

\author{
YANG Hongwei ${ }^{1,2} \&$ XU Chongyu ${ }^{1}$ \\ ( 1 : School of Geographic and Oceanographic Sciences, Nanjing University, Nanjing 210093, P. R. China) \\ ( 2 :Nanjing Institute of Geography and Limnology, Chinese Academy of Sciences, Nanjing 210008, P. R. China)
}

\begin{abstract}
With the hydrological model SWAT, the runoff variation of three representative watersheds in Dongjiang River Basin was simulated. With discharge data from Shengqian, Shuntian and Jiuzhou hydrological stations in $1977-1981$ and $1996-2000$, more sensitive hydrology factors were calibrated and satisfactory simulation results were obtained $\left(R^{2}>0.85,0.68<E_{\mathrm{NS}}<0.75\right)$. The study investigated the influences of LUCC on the hydrological process of the three watersheds. The result shows that: (1) the increase of forest area was the cause of annual runoff decrease; (2) in terms of annual variability, runoff decrease in the wet season while increase in the dry season; (3) the decrease of runoff becomes more notable when the forest area increases with slope $<15^{\circ}$. Keywords: SWAT; LUCC; runoff; representative watersheds in Dongjiang River Basin
\end{abstract}

陆地表层系统最重要的变化之一就是土地利用/覆被的变化 ${ }^{[1]}$, 其变化对区域水循环的影响极为深刻, 是全球环境变化研究的核心领域 ${ }^{[2]}$. 近些年来,因土地利用/覆被变化影响的水文过程的研究得到普遍关 注 ${ }^{[3]}$, 土地利用/ 覆被变化的水文效应研究成为水文学研究的热点 ${ }^{[4]}$. 如 Hibbert ${ }^{[5]}$ 认为森林覆盖的减少导 致年径流量的增加; Sullivan 等 ${ }^{[6]}$ 研究认为农业方式的变化是影响英国 Camel 流域河川径流的主要因素. 诸 多文献表明,水文模型被广泛用于土地利用/覆被变化的水文效应研究 ${ }^{[7]}$. 如 Camorani 等 $^{[8]}$ 运用降雨-径流 模型研究认为洪水发生频率与土地利用/覆被变化有密切关系; Daniel 等 ${ }^{[9]}$ 采用分布式水文模型 WaSiMETH 分析认为 LUCC 在不同尺度上对暴雨径流的影响具有差异性. Jiang 等 ${ }^{[10]}$ 比较了 6 种水文模型模拟东 江流域气候变化对径流的影响. 东江流域不但是广东省经济发达地区,还是河源、惠州、东莞、广州、深圳及 香港等地的重要水源地,研究该地区的土地利用/覆被变化对地表径流影响对流域生态经济协调发展具有 重要意义.

\section{1 研究区域概况}

东江属珠江三大水系之一, 流域总面积为 $35636 \mathrm{~km}^{2}$, 在广东省境内达 $32136 \mathrm{~km}^{2}$, 约占流域总面积的

* 香港特别行政区研究基金会项目(CUHK4627/05H) 资助. 2011-04-20 收稿;2011-06-08 收修改稿. 杨宏伟,男, 1967 年生,博士,副研究员;E-mail:yanghw@ niglas. ac. cn. 
$114^{\circ}$

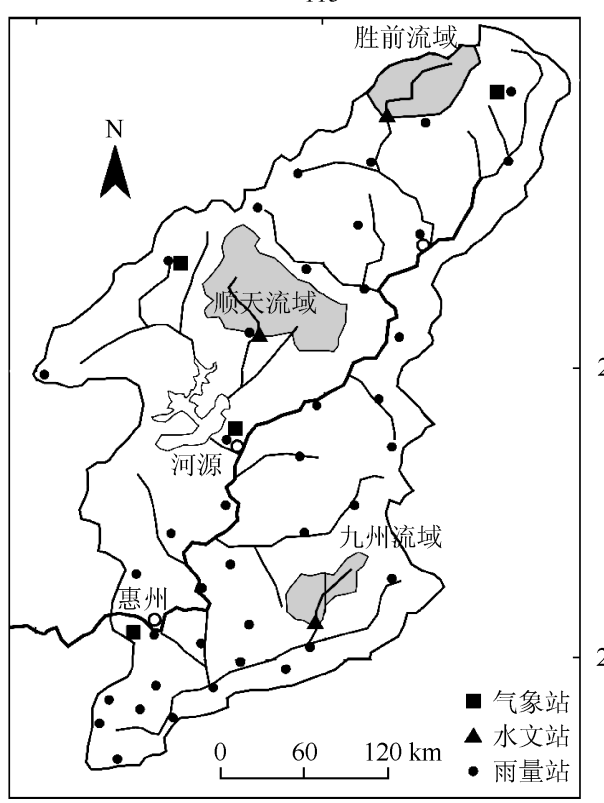

图 1 研究区域示意图

Fig. 1 Location of study area
$90 \%{ }^{[11]}$, 属亚热带湿润季风气候区, 具有明显的干湿 季节, 多年平均气温为 $20.4{ }^{\circ} \mathrm{C}$, 多年平均降水量 $1750 \mathrm{~mm}$, 但降水量年内分配极不均匀: 汛期 (4-9

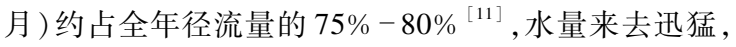
水资源利用十分困难.

近几十年来, 环境变化下的东江流域径流过程发生 了巨大变化. 研究认为在降雨量呈不显著减少趋势的 背景下, 东江流域河源、岭下站径流呈不显著增加趋势 是气候因素和流域植被退化共同作用的结果 ${ }^{[1-12]}$, 而 1990s 以来土地利用/覆被变化引起的流域下垫面条 件变化是影响东江流域径流增加的主要原因. 为了分 析土地覆被变化对流域径流的影响, 本文选取东江三 个典型流域(胜前流域 $667 \mathrm{~km}^{2}$ 、顺天流域 $1363 \mathrm{~km}^{2}$ 和 九州流域 $387 \mathrm{~km}^{2}$ ) (图 1), 分析在不同的土地覆被情 景下流域径流深的变化情况.

\section{2 数据资料与研究方法}

\section{1 数据资料}

东江流域 34 个雨量站, 1970-2000 年的日降水资 料和 $1961-2000$ 年的月雨量资料. 东江三个典型流域 的出口控制站 (胜前、顺天和九州) $1961-2000$ 年的日

径流量资料. 东江流域 7 站 1970-2000 年的日最大风速风向、日降水量、日平均水汽压、日相对湿度、日最高 温度、日最低温度资料. 三个典型流域 1973 年 (MSS)、1986 年及 2003 年 ( TM) 的三期土地利用卫星影像解 译数据; 东江流域 $1: 250000$ 数字地面高程数据; $1: 250000$ 广东省土壤图.

\section{2 研究方法}

SWAT( Soil and Water Assessment Tool) 是一个具有很强物理机制的、流域连续分布式水文模型, 1990s 初, 模型吸取了 CREAMS、GLEAMS、EPIC、SWRRB 等模型的优点, 将 SWRRB 和 ROTO 整合为一个新的模 型, 并增加了敏感性分析、自动校核和不确定性分析模块. 通常 SWAT 模型很少在森林为主导的流域应 用 ${ }^{[13]}$, 但也有采用改进后的 SWAT 模型在不同森林类型为主的流域进行研究 ${ }^{[14-15]}$. 目前利用 SWAT 模型进 行研究的流域面积最小为 $0.395 \mathrm{~km}^{2}$, 最大为 $491700 \mathrm{~km}^{2}$, 可见其具有较强的适用性 ${ }^{[16]}$.

根据研究区域的自然特征、资料收集情况和土地利用/覆被的特征,本文选择改进后的分布式水文模型 SWAT. 根据 Spruill ${ }^{[17]}$ 等对不同尺度流域的比较研究, 认为 SWAT 模型在中小流域尺度月径流模拟的精度较 高. 故本文采用 1996-2000 年水文气象资料, 模拟 1973 年、1986 年和 2003 年土地利用/覆被条件下的逐月 径流量,探讨不同土地利用/覆被变化对月径流量的影响.

\section{3 土地利用/覆被时空变化特征}

三个流域林地和农业用地是土地利用的主要类型,从其空间变化的强度来看, 三个流域存在明显差异. 胜前流域从 $1973-2003$ 年,农业用地变化幅度较小,但林地面积增加幅度较大,从 1973 年的 51. 65\% 增加至 2003 年的 $70.59 \%$; 城镇建设用地 2003 年与 1973 年相比增加了近 40 倍之多,1990s 以后变化尤为突出. 顺 天流域农业用地有所减少, 由 1973 年的 $34.61 \%$ 降至 2003 年的 $29.54 \%$; 林地面积由 1973 年的 $39.39 \%$ 增 加至 2003 年的 $62.28 \%$, 城镇建设用地也有所增加. 九州流域除了林地面积增加较多外, 其他用地变化不大 (表 1). 1985 年作出了“十年绿化广东” 的战略决策, 整个流域森林覆盖率已有较大提高 ${ }^{[18]}$. 
表 $11973-2003$ 年三个典型流域主要土地利用类型面积变化

Tab. 1 Land use area changes in the three watersheds from 1973 to 2003

\begin{tabular}{|c|c|c|c|c|c|c|c|}
\hline \multirow{2}{*}{ 典型流域 } & \multirow{2}{*}{ 年份 } & \multicolumn{2}{|c|}{ 农业用地 } & \multicolumn{2}{|c|}{ 林地 } & \multicolumn{2}{|c|}{ 建设用地 } \\
\hline & & 面积 $\left(\mathrm{hm}^{2}\right)$ & 比例 (\%) & 面积 $\left(\mathrm{hm}^{2}\right)$ & 比例 (\%) & 面积 $\left(\mathrm{hm}^{2}\right)$ & 比例 (\%) \\
\hline \multirow[t]{3}{*}{ 胜前流域 } & 1973 & 14594.22 & 21.88 & 34451.64 & 51.65 & 27.27 & 0.04 \\
\hline & 1986 & 14722.92 & 22.07 & 37980.18 & 56.94 & 41.94 & 0.06 \\
\hline & 2003 & 15011.55 & 22.51 & 47085.66 & 70.59 & 1022.76 & 1.53 \\
\hline \multirow[t]{3}{*}{ 顺天流域 } & 1973 & 47157.12 & 34.61 & 53668.62 & 39.39 & 9.36 & 0.01 \\
\hline & 1986 & 46274.85 & 33.96 & 62170.56 & 45.63 & 86.04 & 0.07 \\
\hline & 2003 & 40247.37 & 29.54 & 84864.51 & 62.28 & 799.11 & 0.65 \\
\hline \multirow[t]{3}{*}{ 九州流域 } & 1973 & 3303.81 & 8.54 & 29363.67 & 75.88 & 35.10 & 0.09 \\
\hline & 1986 & 3076.56 & 7.95 & 30530.60 & 78.89 & 47.61 & 0.12 \\
\hline & 2003 & 2494.35 & 6.45 & 32795.70 & 84.74 & 101.61 & 0.26 \\
\hline
\end{tabular}

\section{4 月径流量模拟}

\section{1 模型参数率定}

选用 $1977-1981$ 年三个流域出口控制站的日径流资料进行参数的率定. SWAT 模型参数多达 60 多个, 首先必须对参数的敏感性进行分析. 通常 SWAT 模型按灵敏度分为: 极高 $(>1.0)$ 、高 $(0.2-1.0)$ 、中 $(0.05$ $-0.2)$ 和低 $(<0.05)$ 四个等级 ${ }^{[18]}$. 运行模型灵敏度分析模块, 通过灵敏性分析, 得知灵敏性因子的重要性, 三个流域的敏感值看出, SCS 径流曲线系数和地表水滞后时间对径流的影响最显著; 土壤可利用水量和土壤 饱和水力传导系数对径流影响也较显著 (表 2). 在灵敏性分析的基础上, 选择对流域产流有影响的参数, 运 行 SWAT 模型的自动校准模块, 得出一整套参数值, 再根据模拟结果进行必要的调整,使产流量模拟值与实 测值吻合较好.

表 2 SWAT 模型主要率定参数

Tab. 2 The main calibrated parameters of SWAT model

\begin{tabular}{|c|c|c|c|c|c|c|c|}
\hline \multirow{2}{*}{ 主要参数 } & \multirow{2}{*}{ 变化范围 } & \multicolumn{2}{|c|}{ 胜前流域 } & \multicolumn{2}{|c|}{ 顺天流域 } & \multicolumn{2}{|c|}{ 九州流域 } \\
\hline & & 敏感值 & 率定结果 & 敏感值 & 率定结果 & 敏感值 & 率定结果 \\
\hline SCS 径流系数 & $35-98$ & 0.77 & 48.70 & 1.69 & 46.80 & 0.38 & 73.33 \\
\hline 地表水滞后时间 (d) & $0-150$ & 1.01 & 0.26 & 0.98 & 2.20 & 1.54 & 0.10 \\
\hline 主河道有效水力传导系数 & $0-150$ & 0.45 & 142.62 & 0.97 & 128.78 & 0.27 & 40.30 \\
\hline 基流 $\alpha$ 系数 & $0-1$ & 0.20 & 0.88 & 0.27 & 0.99 & 0.11 & 0.94 \\
\hline 土壤可利用水量 $(\mathrm{mm})$ & $0-1$ & 0.13 & 0.29 & 0.16 & 0.26 & 0.15 & 0.12 \\
\hline 土壤饱和水力传导系数 & $0-2000$ & 0.09 & 86.21 & 0.16 & 94.47 & 0.14 & 83.81 \\
\hline 主河道曼宁系数 & $0-0.30$ & 0.13 & 0.15 & 0.12 & 0.05 & 0.11 & 0.10 \\
\hline 土壤蒸发补偿系数 & $0-1$ & 0.08 & 0.46 & 0.07 & 1.00 & 0.06 & 0.44 \\
\hline
\end{tabular}

\section{2 模型的校准与验证}

模型的校准和验证通常选用模拟流量和实测流量之间的相关系数 $R^{2}$ 和 Nash-Suttclife 模型效率系数 $E_{\mathrm{NS}}$, 衡量模型模拟值与实测值之间的拟合度. 效率系数的表达式为:

$$
E_{\mathrm{NS}}=1-\sum_{1}^{n}\left(Q_{\mathrm{o}}-Q_{\mathrm{s}}\right)^{2} / \sum_{1}^{n}\left(Q_{\mathrm{o}}-Q_{\text {avg }}\right)^{2}
$$



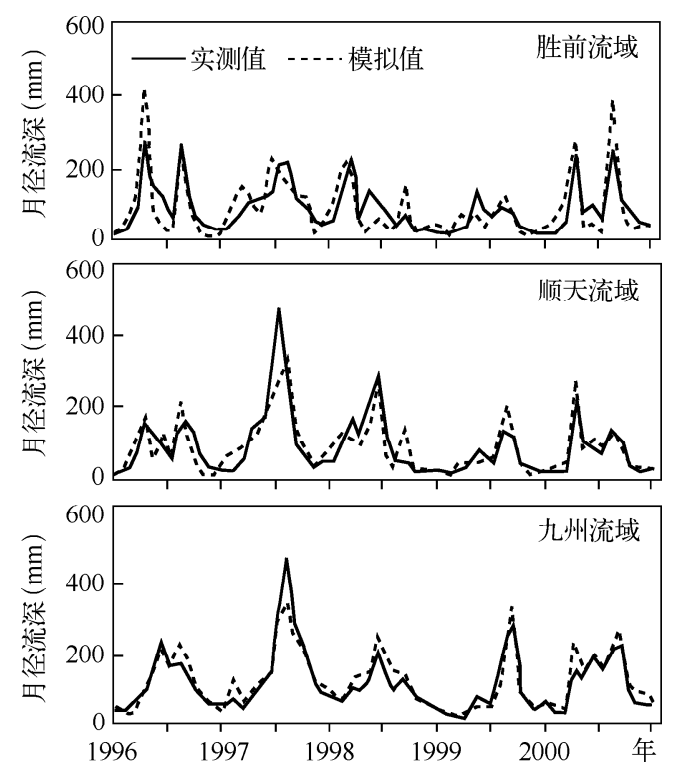

图 2 三个流域模拟月径流量与实测径流量对比

Fig. 2 Comparison between simulated and observed monthly flow in the three watersheds

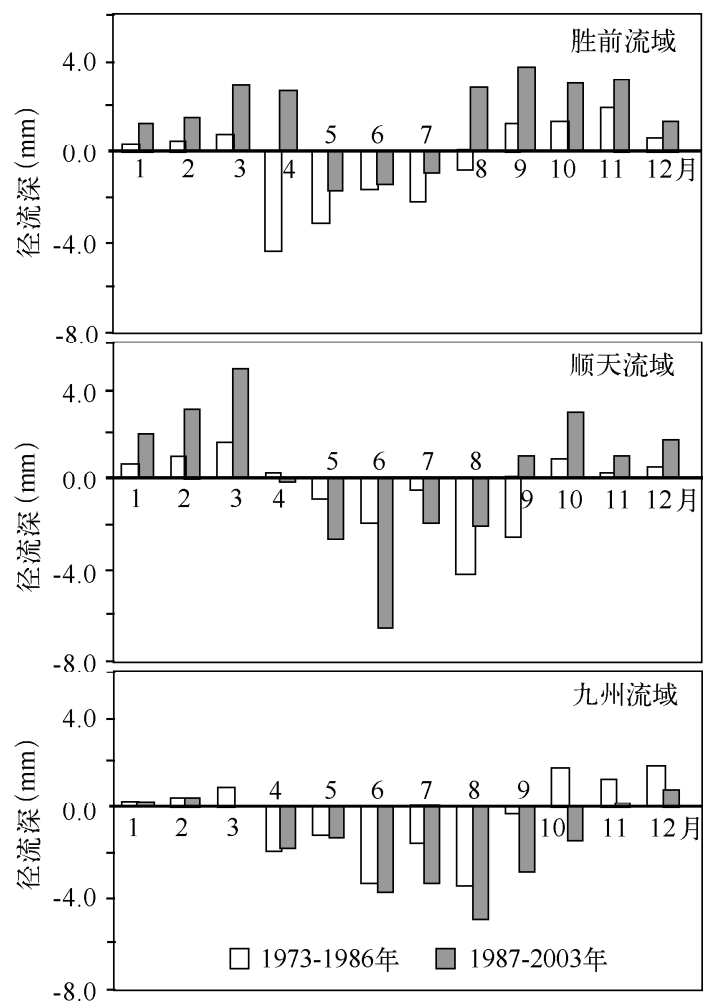

图 3 三个流域不同时段多年平均月径流量

Fig. 3 Variation of the mean monthly flow for the different periods in the three watersheds
式中, $Q_{\mathrm{o}}$ 为流量实测值; $Q_{\mathrm{s}}$ 为流量模拟值; $Q_{\mathrm{avg}}$ 为 流量实测平均值; $n$ 为实测流量数据的长度. $E_{\mathrm{NS}}=$ 1 表示模拟值与实测值完全一致; $E_{\mathrm{NS}}=0$ 表示模拟 效果与实测值的平均值一致; 若 $E_{\mathrm{NS}}<0$, 则模拟结 果无效.

对三个典型流域的地表径流进行模型模拟, 与同时期出口控制站观测资料对比分析; 并用 1996-2000 年的气象、水文资料和 1990s 后期的土 地利用数据进行模型验证.

4. 2.1 模型的校准 根据资料完整性, 选用 $1977-$ 1981 年的气象和水文资料, 以及与之相对应时期的 土地利用/覆被数据进行模型的校准, 在敏感性参 数调整基础上, 三个流域 $1977-1981$ 年逐月径流模 拟与实测值的拟合很好, 相关系数 $R^{2}$ 在 0.9 以上, $P<0.05$, 效率系数 $E_{\mathrm{NS}}$ 在 0.8 以上.

4.2.2 模型的验证用 $1996-2000$ 年的气象、水 文资料和 $1990 \mathrm{~s}$ 后期的土地利用数据作为资料输 人进行模型验证. 流域出口月径流模拟值与实测 流量拟合较好(图 2 和表 3 ), 表明模型在该研究区 模拟产流的适应性较好.

模拟结果显示, 由于三个流域土地利用方式的 变化不同, 年径流变化存在差异. 胜前流域在 $1973-$ 1986 年间年径流深减少 $5.4 \mathrm{~mm}$, 在 $1987-2003$ 年 间增加了 $18.07 \mathrm{~mm}$; 顺天流域在两个时段分别减少 了 $4.45 \mathrm{~mm}$ 和增加了 $2.93 \mathrm{~mm}$; 九州流域在两个时 段分别减少了 $5.62 \mathrm{~mm}$ 和 $17.74 \mathrm{~mm}$. 径流在年内 分配的变化较大 (图 3) : 胜前流域在 1973-1986 年 间,汛期径流减少了 $10.83 \mathrm{~mm}$, 非汛期增加了 $5.42 \mathrm{~mm}$; 在 $1987-2003$ 年间汛期和非汛期分别增 加了 $5.12 \mathrm{~mm}$ 和 $12.96 \mathrm{~mm}$; 顺天流域在 $1973-$ 1986 年间, 汛期减少了 $9.41 \mathrm{~mm}$, 非汛期增加了 $4.96 \mathrm{~mm}$, 在 $1987-2003$ 年间汛期减少了 $12.27 \mathrm{~mm}$, 非汛期增加了 $15.20 \mathrm{~mm}$; 九州流域在 $1973-1986$ 年间, 汛期减少了 $11.63 \mathrm{~mm}$, 非汛期增 加了 $6.01 \mathrm{~mm}$; 在 $1986-2003$ 年间, 汛期减少了 $17.96 \mathrm{~mm}$, 非汛期增加了 $0.23 \mathrm{~mm}$ (表 4).

\section{5 结论与讨论}

采用分布式水文模型, 模拟了东江三个典型流 域的逐月径流量, 结合土地利用/覆被时空变化特 征分析得出以下结论:

(1) 分布式水文模型 SWAT 的参数率定后, 验 证结果的相关系数 $R^{2}$ 在 0.85 以上, 效率系数在 0.70 左右 (表 3 ), 说明 SWAT 模型可用于东江典型 
流域的径流模拟.

表 $31996-2000$ 年模型验证评价

Tab. 3 Summary of the model validation performance for the three watersheds from 1996 to 2000

\begin{tabular}{cccc}
\hline 典型流域 & 相关系数 $\left(R^{2}\right)(P<0.05)$ & 相对误差 $(\%)$ & 效率系数 $\left(E_{\mathrm{NS}}\right)$ \\
\hline 胜前流域 & 0.852 & 17.3 & 0.72 \\
顺天流域 & 0.905 & 19.6 & 0.68 \\
九州流域 & 0.931 & 16.2 & 0.75 \\
\hline
\end{tabular}

表 4 土地利用变化与月径流量增幅 ${ }^{*}$

Tab. 4 Land use changes and variation of the mean monthly flow

\begin{tabular}{|c|c|c|c|c|c|c|c|c|c|}
\hline \multirow{2}{*}{ 典型流域 } & \multirow{2}{*}{ 时间 } & \multicolumn{2}{|c|}{ 农业用地 (\%) } & \multicolumn{2}{|c|}{ 林地(\%) } & \multicolumn{2}{|c|}{ 建设用地 (\%) } & \multicolumn{2}{|c|}{ 月径流深增幅 $(\mathrm{mm})$} \\
\hline & & $<15^{\circ}$ & $>15^{\circ}$ & $<15^{\circ}$ & $>15^{\circ}$ & $<15^{\circ}$ & $>15^{\circ}$ & 汛期 & 非汛期 \\
\hline \multirow[t]{2}{*}{ 胜前流域 } & $1973-1986$ 年 & 0.31 & -0.17 & 5.67 & -0.33 & 0.02 & 0.00 & -10.83 & +5.42 \\
\hline & $1987-2003$ 年 & 0.31 & 0.09 & 9.79 & 3.80 & 1.46 & 0.02 & +5.12 & +12.96 \\
\hline \multirow[t]{2}{*}{ 顺天流域 } & $1973-1986$ 年 & 0.18 & -0.44 & 4.52 & 1.05 & 0.06 & 0.00 & -9.41 & +4.96 \\
\hline & $1987-2003$ 年 & -4.82 & 0.01 & 16.32 & 2.57 & 0.58 & 0.00 & -12.27 & +15.20 \\
\hline \multirow[t]{2}{*}{ 九州流域 } & $1973-1986$ 年 & -0.61 & 0.01 & 2.59 & 0.41 & 0.03 & 0.00 & -11.63 & +6.01 \\
\hline & $1987-2003$ 年 & -1.45 & -0.05 & 5.66 & 0.25 & 0.14 & 0.00 & -17.96 & +0.23 \\
\hline
\end{tabular}

*4-9 月为汛期, $10-2$ 月为非汛期.

(2) 对三个流域不同时期土地利用变化与多年平均月径流深变化的比较分析, 1973-1986 年除了林地 的变化较大外,其它土地利用类型变化较小. 模拟结果显示林地面积的增加,年径流量减少. 年内分配上表 现出枯水期径流明显增加, 丰水期径流明显减少. 其原因可能是随着森林覆盖率的提高, 流域的捾水能力增 强拦截作用加大; $1973-1986$ 年间九州流域 < $15^{\circ}$ 的林地面积增加了 $2.59 \%$, 而 $1987-2003$ 年间增加了 $5.66 \%$,其它土地利用类型面积变化相对较小 (表 4). 两个阶段汛期的径流减少程度存在差异 (表 3 ), 表现 为低坡度 $\left(<15^{\circ}\right)$ 的林地面积增加引起的径流减少作用更为明显.

（3）从 1987-2003 年,尽管胜前流域林地面积增加了 $13.65 \%$, 而建设用地面积增加了 $1.47 \%$ (表 1), 是原来的 40 倍. 汛期的径流深增加了 $5.12 \mathrm{~mm}$ (表 4), 说明建设用地面积的增长, 导致不透水面积增加, 大 大增加了雨季流域的地表径流, 抵消了由林地增加而引起的径流减少的幅度.

本文研究认为应对东江流域土地资源在空间和结构上进行合理配置,减少城镇化过程中对农业生产用 地和林地的影响; 在确保农业用地的基础上,加强对林地等自然植被的保护, 同时加强绿化造林, 改变林业 结构, 尤其是 $<15^{\circ}$ 的林地可以大力发展水源林、经济林, 减少水土流失, 保护水源, 从而提高水资源的利用 效率.

\section{6 参考文献}

[ 1 ] Eric F, Lambin BL, Turner et al. The cause of land-use and land-cover change: moving beyond the myths. Global Environmental Change, 2001, 11: 261-269.

[2] 李秀涁. 全球环境变化的核心领域一土地利用/土地覆被变化的国际研究动向. 地理学报, 1996, 51(6): 553-558.

[ 3 ] 史培军, 袁 艺, 陈 晋. 深圳市土地利用变化对流域径流的影响. 生态学报, 2001, 21(7):1041-1049.

[ 4 ] De Roo A, Odijk M, Schmuck GE et al. Assessing the effects of land use changes in the Meuse and Oder catchment. Physics and Chemistry of the Earth, 2001, 26(7-8) : 593-599.

[ 5 ] Hibbert A. Forest treatment effects on water yield. In: Sopper WE, Lull HW, eds. International symposium on forest hydrology. Oxford: Pergamon Press, 1967: 813.

[ 6 ] Sullivan A, Ternan JL, Williams AG. Land use change and hydrological response in the Camel catchment, Cornwall. Ap- 
plied Geography, 2004, 24 : 119-137.

[ 7 ] Hundecha Y, Bárdossy A. Modeling of the effect of land use changes on the runoff generation of a River Basin through parameter regionalization of a watershed model. Journal of Hydrology, 2004, 292 : 281-295.

[ 8 ] Camorani G, Castellarin A, Brath A. Effects of land-use changes on the hydrologic response of reclamation systems. Physics and Chemistry of the Earth, 2005, 30: 561-574.

[ 9 ] Daniel N, Fritsch U, Bronstert A. Land-use impacts on storm-runoff generation: scenarios of land-use change and simulation of hydrological response in a meso-scale catchment in SW-Germany. Journal of Hydrology, 2002, 267 : 80-93.

[10] Jiang T, Chen YD, Xu CY at al. Comparison of hydrological impacts of climate change simulated by six hydrological models in the Dongjiang Basin, South China. Journal of Hydrology, 2007, 336(3-4) : 316-333.

[11] 陈晓宏, 王兆礼. 东江流域土地利用变化对水资源的影响. 北京师范大学学报 (自然科学版), 2010,46 (3) : 311-316.

[12] 王兆礼, 陈晓宏, 杨 涛. 近 50a 东江流域径流变化及影响因素分析. 自然资源学报, 2010, 125 (18): 1365-1374.

[13 ] Fohrer N, Haverkamp S, Eckhardt K et al. Hydrologic response to land use changes on the catchment scale. Physics and Chemistry of the Earth, 2001, 26(7-8): 577-582.

[14] Wattenbach M, Hattermann F, Weng R et al. A simplified approach to implement forest eco-hydrological properties in regional hydrological modeling. Ecological Modelling, 2005, 187: 40-59.

[15] Kirby JT, Durrans SR. PnET-II3SL/SWAT: Modeling the combined effects of forests and agriculture on water availability. Journal of Hydrology, 2007, 12 (3) : 319-326.

[16] Gassman PW, Reyes MR, Green CH et al. The soil and water assessment tool:historical development, application and future research directions. Transactions of the ASABE, 2007, 50(4) : 1211-1250.

[17] Spruill CA, Workman SR, Taraba JL. Simulation of daily and monthly stream discharge from small watersheds using the SWAT model. Transactions of the ASABE, 2000, 43(6): 1431-1439.

[18] 朱 丽, 秦富仓, 姚云峰等. SWAT 模型灵敏性分析模块在中尺度流域的应用. 水土保持研究, 2011, 18(1): 161-165. 